\title{
Vaccinomics Approach for Designing Potential Peptide Vaccine by Targeting Pyruvate Kinase of Madurella Mycetomatis
}

Aya Yusri A. Manofali 1,7 *, Ismail M. A. I. 2,7 * , Reem E. Talha ${ }^{1,7}$, Zahra A. Neel 1,7, Ali A. Ali Elamin 1,7 Alghzali Altayeb M. Abdalla ${ }^{3,7}$, , Alaa I. Mohamed 4,7, Al- Khansa'a M. Othman ${ }^{4,7}$, Dalia A. M. Hamid ${ }^{1,7}$ Sanaa Bashir $^{5,7}$, Mohammed Shihabeldin ${ }^{6,7}$, Mohammed A. Hassan ${ }^{7}$

* Equally contributed

${ }^{1}$ Faculty of Medicine and Health Sciences, Omdurman Islamic University, Sudan

${ }^{2}$ Department of Medical Microbiology, Faculty of Medicine, University of Khartoum, Sudan

${ }^{3}$ Faculty of Anaesthesia, University of Medical Science and Technology, Sudan

${ }^{4}$ Department of Microbiology, Faculty of Medical Laboratory Sciences, Omdurman Islamic University, Sudan

${ }^{5}$ Department of Zoology, Faculty of Science, University of Khartoum, Sudan

${ }^{6}$ Department of Medical Microbiology, Faculty of Medical Laboratory Sciences, Sudan International University, Sudan

${ }^{7}$ Department of Applied Bioinformatics, Africa City of Technology, Sudan

\section{Abstract:}

Background: Mycetoma is one of the neglected tropical diseases that considered as a public health problem with socioeconomic impact in several developing countries. There is no effective treatment or a vaccine for it, thus the aim of this study is to design a peptide-based vaccine against Madurella mycetomatis infection via in silico approaches, using the immunogenic site Pyruvate kinase (PK).

\section{Material and Methods:}

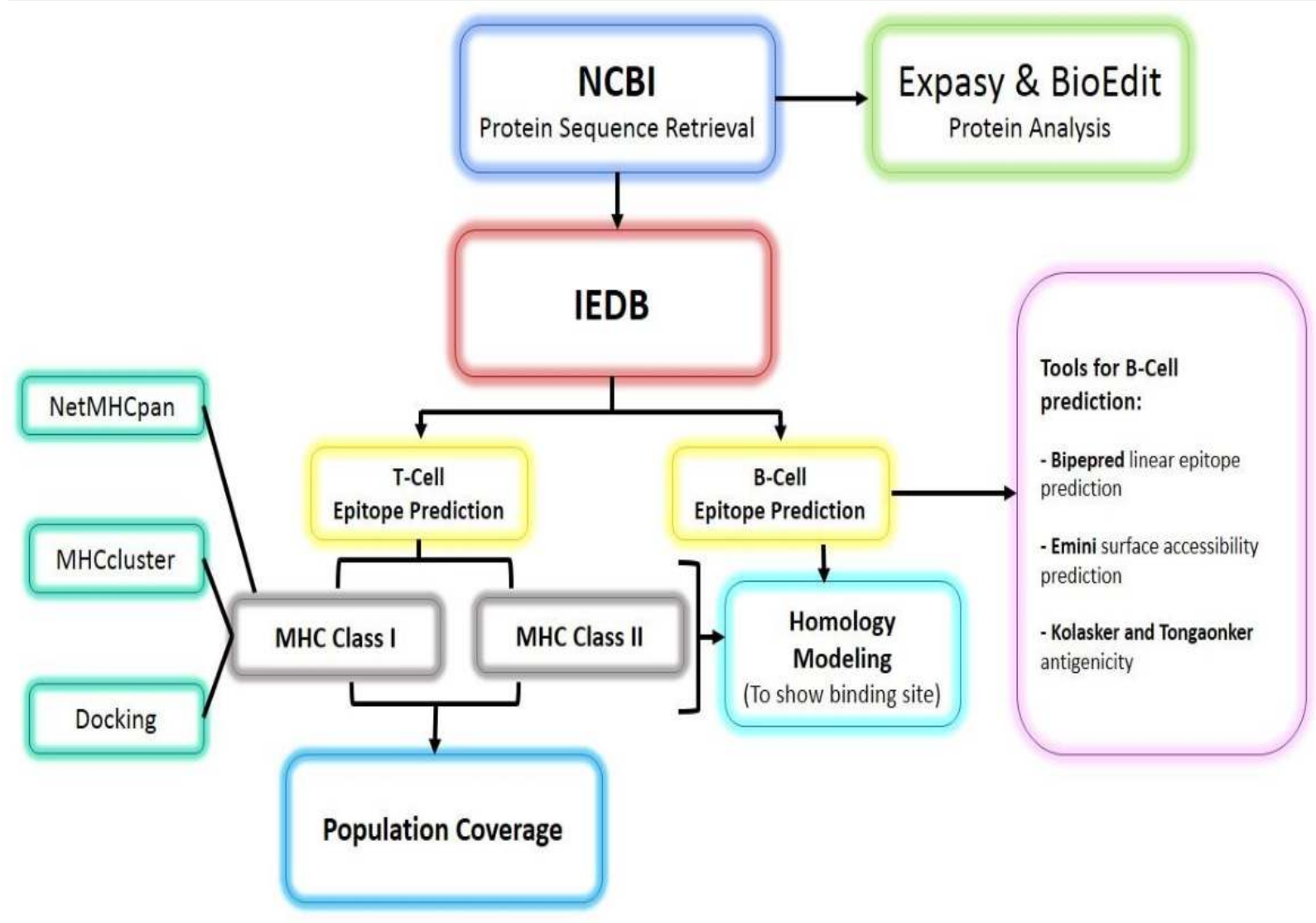

Figure (1): Peptide-based vaccine designation steps.

Result and Discussion: Three epitopes predicted for B cell (102GSYPSEAV ${ }^{109 ，}{ }^{214}$ DFTKV V $^{218 ，}{ }^{117}$ LKAENSIPY $\left.^{125}\right)$ as peptide-based vaccine.

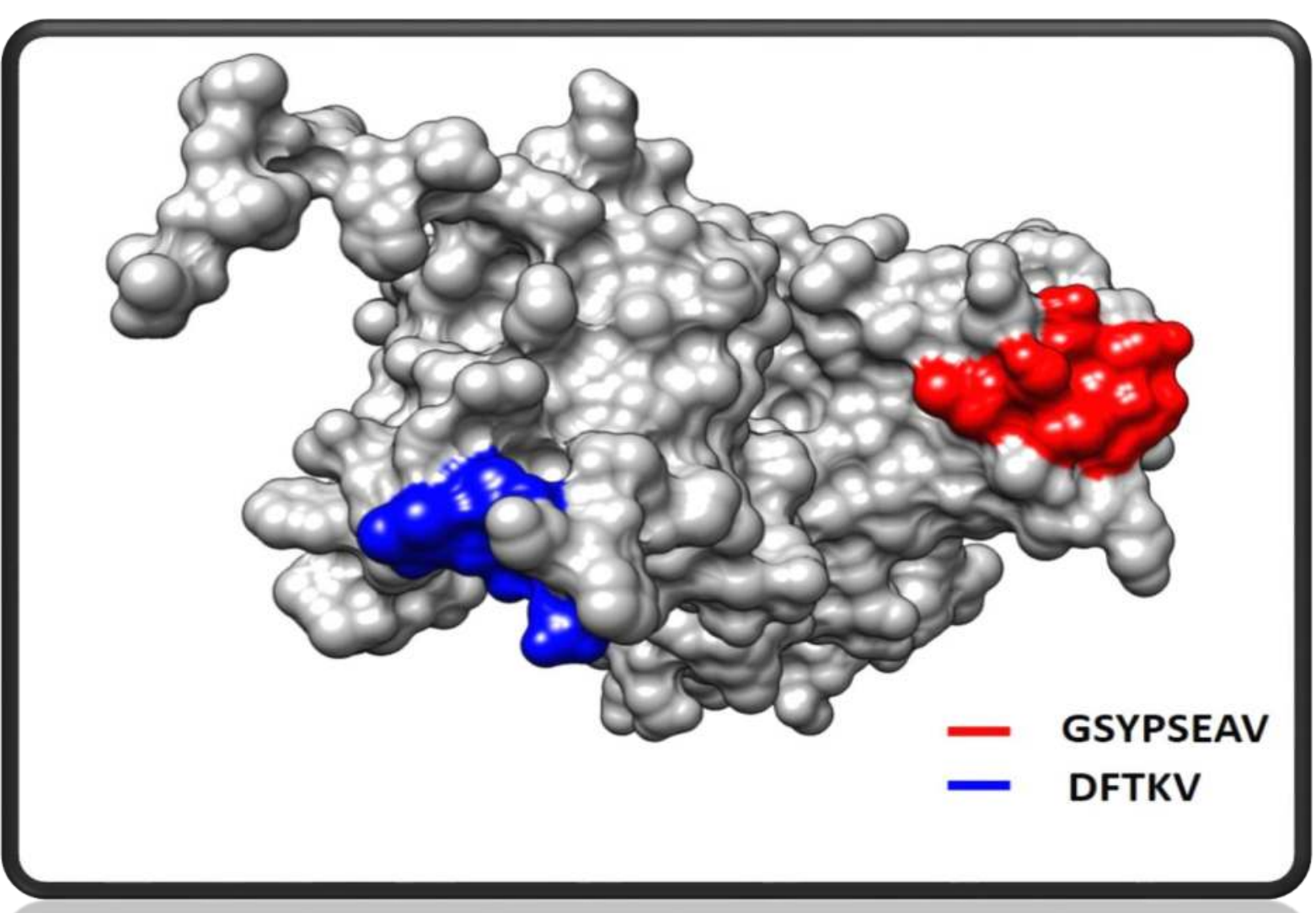

Figure (2): B-cell promising epitopes at molecular level of Pyruvate kinase protein of Madurella mycetomatis. UCSF Chimera version 1.8 was used.
Four shared epitopes $\left({ }^{117}\right.$ LKAENSIPY ${ }^{125}$, ${ }^{197}$ LYRGVYPFL $^{205}$, ${ }^{198}$ YRGVYPFLF ${ }^{206}$, ${ }^{225}$ IKWGLSHAI ${ }^{233}$ ) between MHC-I and MHC-II with epitope set $94.62 \%$ Worldwide and $92.38 \%$ in Sudan. Moreover, one shared epitope $\left({ }^{\mathbf{1 1 7}}\right.$ LKAENSIPY $\left.{ }^{125}\right)$ predicted in B-cell, MHC-I and MHC-II with high population coverage World combined MHC-I and MHC-II $77.92 \%$ and $57.78 \%$ in Sudan.

This is the first study was done to predict peptide-based vaccine against Pyruvate kinase of Madurella mycetomatis, so this study will provide a strong base for development of vaccine after in vivo and in vitro studies confirmation of all this candidate epitopes as effective peptide vaccine.

Table (1): Population coverage of proposed epitope in MHC class I combined with MHC class II in World and Sudan

\begin{tabular}{ccccc}
\hline Epitope & Start & End & $\begin{array}{c}\text { Population } \\
\text { Coverage } \\
\text { World }\end{array}$ & $\begin{array}{c}\text { Population } \\
\text { Coverage } \\
\text { Sudan }\end{array}$ \\
\hline YRGVYPFLF & 198 & 206 & $77.18 \%$ & $78.32 \%$ \\
LKAENSIPY & 117 & 125 & $57.78 \%$ & $77.92 \%$ \\
LYRGVYPFL & 197 & 205 & $49.67 \%$ & $73.86 \%$ \\
IKWGLSHAI & 225 & 233 & $43.31 \%$ & $71.35 \%$ \\
\hline
\end{tabular}

Epitope set

$94.62 \%$ 92.38\%

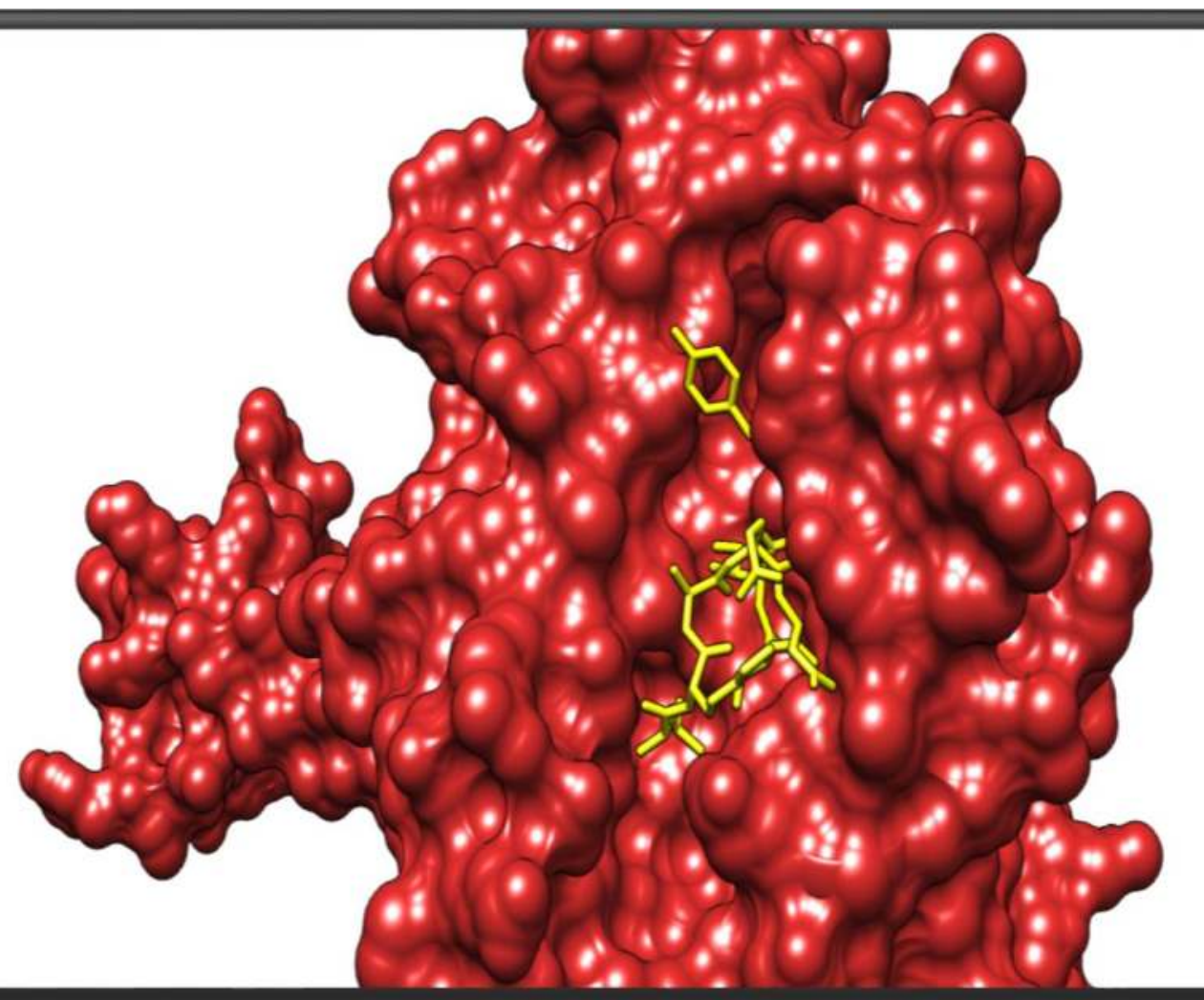

Figure (3): Interaction of ${ }^{\mathbf{1 1 7}}$ LKAENSIPY $^{\mathbf{1 2 5}}$ with MCH class I antigen HLAA (Accession number: AAC04322) Ligand (LKAENSIPY): yellow color, Receptor (MCH class I antigen HLA-A) firebrick in color. PEP-FOLD 2.0 and PATCHDOCK Beta 1.3 version were used. 